
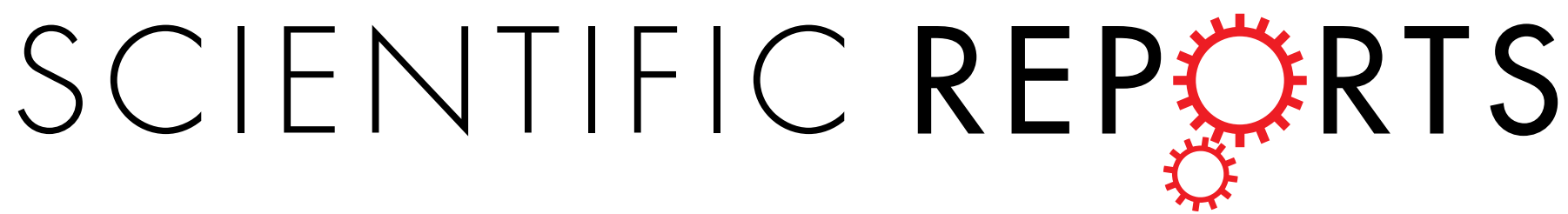

\title{
OPEN Viable offspring obtained from Prm1-deficient sperm in mice
}

\section{Naoki Takeda ${ }^{1}$, Kazuya Yoshinaga ${ }^{2}$, Kenryo Furushima ${ }^{3}$, Kazufumi Takamune ${ }^{4}$, Zhenghua Li $^{5}$, Shin-ichi Abe ${ }^{6}$, Shin-ichi Aizawa ${ }^{7}$ \& Ken-ichiYamamura ${ }^{8}$}

Received: 10 March 2016

Accepted: 18 May 2016

Published: 02 June 2016

Protamines are expressed in the spermatid nucleus and allow denser packaging of DNA compared with histones. Disruption of the coding sequence of one allele of either protamine 1 (Prm1) or Prm2 results in failure to produce offspring, although sperm with disrupted Prm1 or Prm2 alleles are produced. Here, we produced Prm1-deficient female chimeric mice carrying Prm1-deficient oocytes. These mice successfully produced $\mathrm{Prm1}^{+1-}$ male mice. Healthy $\mathrm{Prm1}^{+/-}$offspring were then produced by transferring blastocysts obtained via in vitro fertilization using zona-free oocytes and sperm from Prm1 ${ }^{+l-}$ mice. This result suggests that sperm lacking Prm1 can generate offspring despite being abnormally shaped and having destabilised DNA, decondensed chromatin and a reduction in mitochondrial membrane potential. Nevertheless, these mice showed little derangement of expression profiles.

Chromosomal DNA is compacted into the microscopic space of the cell nucleus primarily by histones in somatic cells and by protamines in sperm. Histones are highly alkaline proteins, whereas protamines are small arginine-rich proteins. During spermatid differentiation (spermiogenesis), nuclear remodelling and condensation are associated with the sequential displacement of histones by transition proteins and then by protamines, namely protamine 1 (PRM1) and protamine 2 (PRM2) ${ }^{1}$. Whereas PRM1 is present in all mammals and many other species, PRM2 is found in all primates-but only in certain rodents and a few other mammals. Protamines allow for denser packaging of DNA in the spermatozoon compared with histones. Therefore, protamines are believed to play important roles in chromatin condensation, suppression of transcription, protection of the haploid male genome, determination of sperm shape, and production of offspring. Humans and mice have three protamine genes: Prm1, Prm2, and Prm3. In mice, PRM1 is an arginine- and cysteine-rich protein of 50 amino acids, whereas PRM2 is rich in histidine and has 106 amino acids. It is likely that the Prm2 gene is derived from a duplication of the Prm 1 gene. Approximately $70 \%$ of the protamine in mouse sperm and $50 \%$ of that in human sperm is $\mathrm{PRM}_{2}{ }^{2}$. Prm 2 has several features that distinguish it from Prm1. Prm2 encodes a precursor protein that binds to DNA and then undergoes proteolytic processing, which results in the removal of approximately $40 \%$ of the amino terminus of the molecule to yield a mature form of 63 amino acids ${ }^{3}$. PRM2 also differs from PRM1 in its ability to bind zinc ${ }^{4}$. The relationships between Prm1 and Prm2 is not well understood. Gene-knockout experiments have shown that the presence of both Prm1 and Prm2 is required for proper spermatid maturation and male fertility in mice 5 . In addition, maintaining the correct proportion of the two protamines in mice is critical for maintaining the integrity of sperm chromatin. Mouse sperm deficient in Prm 2 have increased DNA damage, incomplete chromatin condensation, and other defects that block embryonic development beyond the blastocyst stage ${ }^{6}$. Alterations in the composition and structural organisation of sperm chromatin (to which PRM1 and PRM2 contribute) may affect both fertilisation and early events in embryonic development ${ }^{7}$. Prm 3 encodes a putative 104-amino acid polypeptide with high glutamic acid content ${ }^{8}$ that is localized in the cytoplasm instead

${ }^{1}$ Division of Developmental Genetics, Institute of Resource Development and Analysis, Kumamoto University, 2-2-1 Honjo, Kumamoto 860-0811, Japan. 'Department of Anatomy, Graduate School of Health Sciences, Kumamoto University, 4-24-1 Kuhonji, Kumamoto 862-0975, Japan. ${ }^{3}$ Department of Molecular Cell Biology and Molecular Medicine, Institute of Advanced Medicine, Wakayama Medical University, 811-1 Kimiidera, Wakayama 641-8509, Japan. ${ }^{4}$ Department of Biological Sciences, Graduate School of Science and Technology, Kumamoto University, 2-39-1 Kurokami, Kumamoto 860-8555, Japan. ${ }^{5}$ Department of Histology and Embryology, Harbin Medical University, Harbin 150081, China. ${ }^{6}$ Kumamoto Health Science University, 325 Izumi-machi, Kita-ku, Kumamoto 861-5598, Japan. ${ }^{7}$ Center for Developmental Biology, RIKEN Kobe, 2-2-3 Minatojima Minamimachi, Chuo-ku, Kobe 650-0047, Japan. ${ }^{8}$ Yamamura Project Laboratory, Institute of Resource Development and Analysis, Kumamoto University, Kumamoto 860-0811, Japan. Correspondence and requests for materials should be addressed to K.-i.Y. (email: yamamura@gpo.kumamoto-u.ac.jp) 
of the nucleus ${ }^{9}$. Although the sperm from Prm $^{-1-}$ mice exhibit reduced motility ${ }^{9}$, Martin-Coello et al ${ }^{10}$ found that PRM3 is not a true protamine and is not involved in chromatin condensation.

In humans, an initial mutational analysis of the protamine genes suggested that the presence of pathogenic mutations in these genes was a rare cause of infertility ${ }^{11-18}$. However, a single-nucleotide polymorphism (SNP; G197T) that results in an arginine-to-serine change in the highly conserved arginine clusters needed for normal DNA binding has been found in $10 \%$ of unrelated infertile patients whose sperm were phenotypically similar to those from protamine-deficient mice ${ }^{19}$.

In mice, Cho et al. ${ }^{5,6}$ reported that male chimeras produced by an injection of $\mathrm{Prm} 1^{+/-}$embryonic stem (ES) cells or Prm2 $2^{+/-}$ES cells into C57BL/6N blastocysts could not transmit either the mutant or wild-type allele derived from the $\mathrm{Prm}^{+/-}$or $\mathrm{Prm}^{+/-}$ES cells to the next generation. These authors also performed intra-cytoplasmic sperm injection using Prm2-deficient sperm; however few eggs were able to develop to the blastocyst stage. Cho et al. ${ }^{5,6}$ were unable to obtain $\mathrm{Prm} 1^{+/-}$or $P r m 2^{+/-}$heterozygous mice using natural mating or intracytoplasmic sperm injection.

Here, for the first time to our knowledge, we successfully obtained female chimeric mice carrying Prm1-deficient oocytes, and subsequently obtained $\mathrm{Prm}^{+/-}$male mice. Healthy Prm1 ${ }^{+/-}$offspring were born by transferring blastocysts obtained by in vitro fertilization using zona-free oocytes with sperm from these Prm $1^{+/-}$ mice. This achievement suggests that the DNA is not severely damaged in sperm lacking Prm1. Although the sperm are abnormally shaped and exhibit DNA destabilisation, chromatin decondensation, and reduced mitochondrial membrane potential, there is little derangement of expression profiles.

\section{Results}

Generation of Prm1 heterozygous mice. Following electroporation with the targeting vectors, 569 neo-resistant clones were screened for targeted recombination using Southern blot analysis. With probe A, three clones (Nos. A36, F6, and $\phi 18$ ) yielded 10.9-kb and 9.6-kb bands when digested with EcoRI/EcoRV (Supplementary Fig. 1). All three clones yielded $9.0-\mathrm{kb}$ and $7.7-\mathrm{kb}$ bands or $7.3-\mathrm{kb}$ and $6.0-\mathrm{kb}$ bands when digested with ApaL1 and ScaI, respectively (Supplementary Fig. 1). These patterns indicated the presence of the targeted allele.

As previously reported ${ }^{5}$, heterozygous $\operatorname{Prm} 1$-deficient mice $\left(\mathrm{Prm1}^{+/-}\right)$cannot be obtained by natural mating between chimeric male mice produced using targeted ES cells and wild-type mice. Because we expected that oocyte formation might not be affected by protamine deficiency, we used TT2-XO ES cells ${ }^{20}$ to determine whether we could generate female $\mathrm{Prm}^{+/-}$mice. Three independent targeted ES clones were injected into eight-cell stage embryos to generate chimeric mice. Female chimeric mice from three clones successfully produced male and female Prm $1^{+/-}$offspring. Female F1 mice from ES clone No. A36 were backcrossed to C57BL/6J for a further six generations. All male $\mathrm{Prm}^{+/-}$mice used in the following experiments were from the sixth generations or later.

As expected, $\mathrm{Prm}^{+1-}$ males did not sire offspring by natural mating. We therefore attempted in vitro fertilization (IVF) using sperm from Prm $1^{+/-}$mice. However, no fertilised eggs were obtained. Because sperm from the Prm $1^{+/-}$mice might not penetrate the zona pellucida, we performed IVF with zona-free oocytes. This procedure yielded fertilised eggs (fertilisation rate 73\%; 62/85). Eighty fertilised eggs were then cultured in vitro. Of these, 34 developed to the two-cell stage and 23 to the blastocyst stage. These 23 blastocysts were transferred into uteri and yielded 16 foetuses on embryonic day 12.5. Surprisingly, six embryos (37.5\%) were identified as Prm $1^{+/-}$mice by polymerase chain reaction (PCR). We then further investigated whether the Prm ${ }^{+/-}$males could sire offspring. In an initial experiment, we transferred two-cell-stage embryos into the oviducts of foster mothers at 0.5 -days post-coitus. However, no offspring were obtained. Next, we transferred 50 four-cell-stage embryos into the oviducts of foster mothers at 0.5 days post-coitus. Seven mice were born, three of which were Prm $1^{+/-}$. These results clearly suggest that Prm1-deficient sperm can generate offspring. Subsequently, Prm1 ${ }^{+/-}$offspring were obtained either by transferring blastocysts developed from in vitro fertilised eggs into the uterus of foster mothers at 2.5 days post-coitus or by mating female $\operatorname{Prm} 1^{+/-}$mice with male $\operatorname{Prm} 1^{+/+}$mice.

$\operatorname{Prm}^{+/+}$males $(\mathrm{n}=6)$ and $\operatorname{Prm} 1^{+/-}$males $(\mathrm{n}=7)$ did not differ in terms of external appearance, body weight, testis weight, or epididymis weight (Supplementary Table 1).

Basic nuclear protein expression. We performed the following analyses on the Prm1 $1^{+/-}$mice. To assess the effect of Prm1 deficiency, the expression levels of the sperm-specific nuclear protein genes Prm1, Prm2, and Tnp1 in sperm from the cauda epididymis and vas deferens were analysed using RT-PCR. The expression levels of all of these genes were slightly reduced (Fig. 1a). Western blot analyses were performed using either anti-PRM1 or anti-PRM2 antibodies and showed that the level of PRM1 in Prm1 ${ }^{+/-}$mice was reduced to approximately half that in Prm1 ${ }^{-1-}$ mice (Fig. 1b). As expected, the precursor form of PRM2 was detected in the Prm1 $1^{+/-}$mice, whereas production of the mature form of RPM2 was greatly reduced (Fig. 1b).

Protamine status in Prm $\mathbf{1}^{+I-}$ mice. Chromomycin A3 (CMA3) competes with protamines for binding to the minor groove of $\mathrm{DNA}^{21}$. Therefore, CMA3 is a simple and useful tool for assessing the packaging of sperm chromatin and allows indirect visualization of protamine deficiency. Flow cytometry histogram analysis showed low fluorescence intensity with a single peak in $\mathrm{Prm}^{+/+}$mice, indicating normal chromatin packaging. In $\mathrm{Prm}^{+/-}$mice, biphasic peaks, with one at the same fluorescence and the other at a stronger fluorescence compared with the wild-type samples, were observed, indicating the presence of two types of sperm in $\mathrm{Prm}^{+/-}$mice: one with the same PRM content as the wild-type sperm and the other with a lower PRM content (Fig. 2a).

The thiol-disulphide status of spermatozoa can be measured using the fluorescent thiol-labelling agent monobromobimane $(\mathrm{mBBr})$. Because protamine is a thiol protein and thiol oxidation occurs in protamine during sperm epididymal maturation, $\mathrm{mBBr}$ can be used to determine the sperm protamine content and thiol-disulphide status in $\mathrm{Prm}^{+/-}$mice. $\mathrm{mBBr}$-labelled spermatozoa from the cauda epididymis and vas deferens were analysed 
a

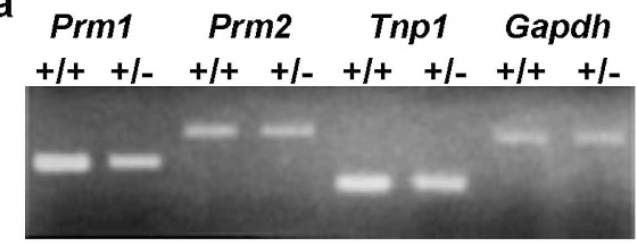

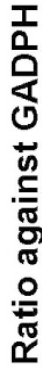

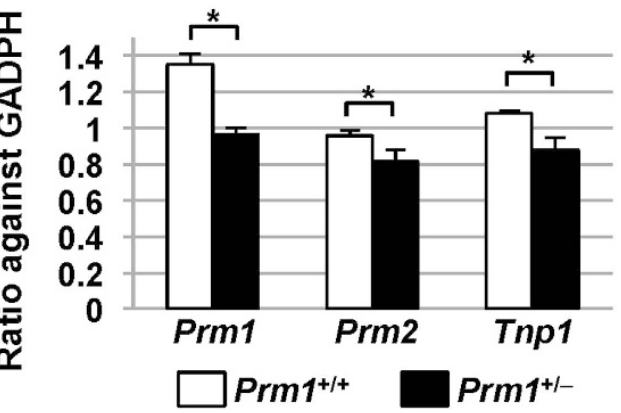

b

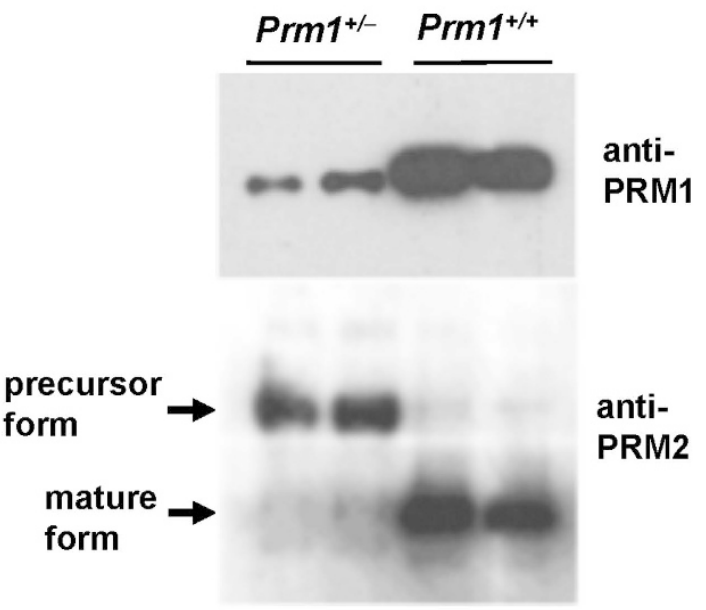

Figure 1. Targeted mutation at the Prm1 locus. (a) RT-PCR analysis of the mRNAs encoding basic proteins in the cauda epididymis and vas deferens. (b) Western blot analysis. The levels of PRM1 were reduced and the levels of the precursor forms of PRM2 were elevated in the $P r m 1^{+l-}$ mice. Statistical analyses were performed using unpaired Student's t-tests $\left({ }^{*} P<0.05,{ }^{* *} P<0.01\right)$.

via flow cytometry before and after 1,4-dithiothreitol (DTT) treatment. The mean mBBr fluorescence intensity in the $P r m 1^{+/+}$mice was significantly higher than that in the $P r m 1^{+/-}$mice before DTT treatment $(P<0.05$; Fig. 2b), indicating that the Prm $1^{+/-}$mice had a lower content of free thiols. Interestingly, the flow cytometry histogram of the $\mathrm{Prm}^{+/-}$mice was broad or biphasic, whereas that of the $\mathrm{Prm}^{+/+}$mice had a single peak, indicating that the $\mathrm{PrmI}^{+/-}$mice had two types of sperm: one with low free thiol and the other with the same thiol level as the wild-type sperm. The total amount of sperm thiols reflects the total amount of PRM and can be measured after treatment with DTT. The total thiol intensity of the $P r m 1^{+/-}$mice was approximately $80 \%$ of that of the Prm $1^{+1+}$ mice after the DTT treatment $\left(P<0.01\right.$; Fig. 2c). These results suggest that $P r m 1^{+1-}$ mice have sperm populations with two different disulphide states (arising from the absence or presence of Prm1), thereby resulting in low levels of free and total thiols. Alternatively, the biphasic peaks might be a secondary effect of altered nuclear integrity or degenerated PRM1-deficient sperm because sperm in the cauda epididymis of Prm1 $1^{+/-}$mice are often phenotypically abnormal and their numbers are reduced. In fact, the heterogeneous appearance on comet assay of sperm from Prm1 $1^{+/}$mice (Fig. 3a) is consistent with this explanation.

DNA damage and stability in sperm from Prm1 $^{+/-}$mice. Sperm recovered from the cauda epididymis and vas deferens were analysed for DNA damage using a comet assay. Sperm from the Prm1 ${ }^{+/-}$mice showed larger comets than sperm from the wild-type mice (Fig. 3a). The comet assay parameters (median and interquartile range) for the $\operatorname{Prm} 1^{+/+}$mice $(n=12)$ were as follows: tail length, 0 (0 to 15); \% tail DNA, 11.9 (5.60 to 13.3); and tail moment, 0 (0 to 1.1). By contrast, the parameters for the Prm1 ${ }^{+/-}$mice $(n=19)$ were as follows: tail length, 23.0 (6.0 to 57.5); \% tail DNA, 22.8 (14.0 to 57.2); and tail moment, 7.4 (0.8 to 33.4) (Fig. 3b). There were significant differences between the two genotypes in terms of tail length and tail moment $(P<0.01)$ as well as the $\%$ tail DNA $(P<0.05)$.

A sperm chromatin structure assay (SCSA) was used to examine the sperm DNA integrity via flow cytometry of acridine orange (AO)-stained sperm. To assess the susceptibility of sperm chromatin to low pH-induced denaturation, the SCSA was performed by a previously described method ${ }^{22}$. AO intercalates with intact double-stranded DNA to emit green fluorescence, whereas the dye emits red fluorescence when associated with RNA or denatured DNA. Examination of the fluorescence spectra of sperm from the Prm $1^{+1+}$ mice showed one group that emitted mostly green fluorescence, whereas the fluorescence spectra of the sperm of the $\mathrm{Prm}^{+/-}$mice showed two groups-one emitting green and the other red fluorescence (Fig. 3c)—suggesting the presence of two types of sperm. Sperm from the Prm $1^{+1-}$ mice showed biphasic peaks of red fluorescence, which represent large numbers of sperm with denatured DNA (Fig. 3d). The percentage of cells outside the main population was $1.35 \%$ in the Prm $^{+1+}$ mice and $32.7 \%$ in the Prm $1^{+1-}$ mice (Fig. 3d). The results of both the comet assay and the SCSA show reduced chromatin integrity, which destabilises the DNA packaging of the sperm of $P r m 1^{+l-}$ mice.

Sperm morphology. To examine the sperm morphology, we first performed eosin staining. Abnormalities can be classified depending on the site of abnormality (i.e., head or tail). A typical sperm is shown in Fig. 4a. Hairpin loops (Fig. 4b) were frequently observed in the sperm of both Prm $1^{+/+}$and Prm $1^{+/-}$mice. Head abnormalities included a "hammer head" appearance (Fig. 4c) and a tail attached to a bent head (Fig. 4d). Abnormalities were more frequent in the tail region of $\mathrm{Prm}^{+1-}$ mice and included coiled (Fig. 4e), fused (Fig. 4f), and rough-surfaced (Fig. 4g,h) tails. Tail abnormalities were often accompanied by a needle-like structure (Fig. 4h). Bent heads were often associated with head distortion. 
a

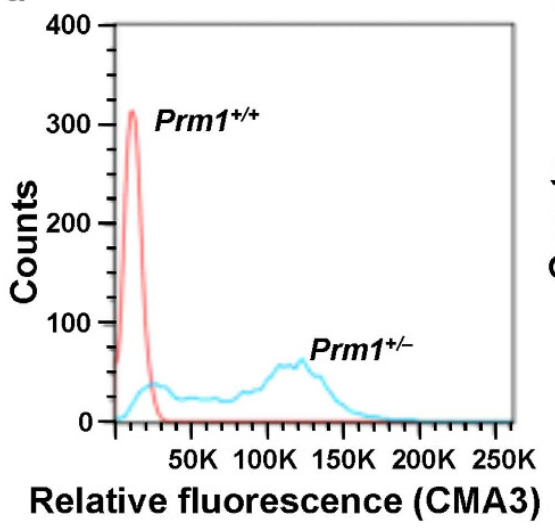

b

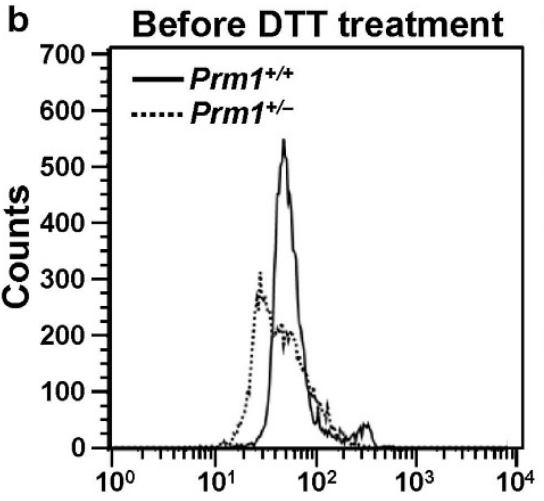

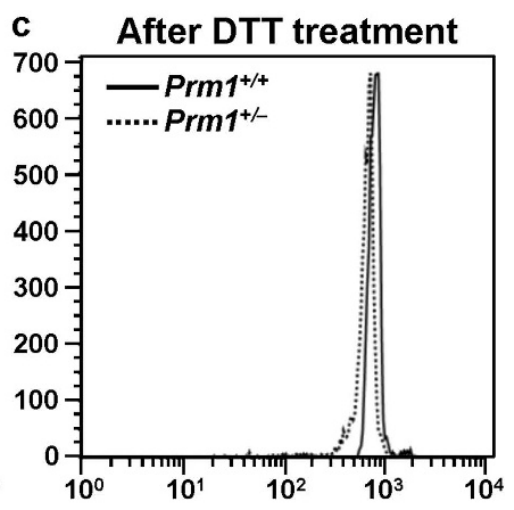

Relative fluorescence (mBBr)

Figure 2. Protamine deficiency. (a) CMA3 assay. Flow cytometric plots showing nuclei of spermatozoa stained with CMA3. CMA3 is a fluorochrome that detects protamine deficiency in loosely packed chromatin. (b,c) Thiol labelling assay. Mean fluorescence intensities in the $\mathrm{Prml}^{+/-}$sperm before and after DTT treatment were lower than those in the $\mathrm{Prm}^{+/+}$sperm, indicating a lower content of free and total thiols in the Prm1 ${ }^{+/-}$sperm.

Similar sperm abnormalities were observed via scanning electron microscopy (SEM) (Fig. 4i [normal sperm] to 1); they included coiled tail (Fig. 4j) and a fused tail with a needle-like structure (Fig. 4k,l). SEM images of a rough-surfaced tail are shown in Fig. $4 \mathrm{~m}, \mathrm{n}$. We observed fine fibres protruding from the periphery of the broken tails (Fig. 4k,l).

Eosin staining revealed that $22.3 \%$ of the epididymal spermatozoa from the $P r m 1^{+/+}$mice were abnormal, compared with $74.6 \%$ of those from the $\operatorname{Prm} 1^{+/-}$mice $(P<0.01$; Fig. 4o). In addition, the hairpin, head + tail and tail sperm abnormalities were all significantly more common in the $\operatorname{Prm} 1^{+/-}$mice than in the Prm $1^{+/+}$ mice $(P<0.01$; Fig. 4o). Therefore, the haploid insufficiency of PRM1 increased the rate of abnormal sperm morphologies.

Transmission electron microscopy (TEM) was used to determine the appearance of chromatin, the organisation and placement of flagellar components, and the association between the acrosome and the nucleus. The sperm chromatin was tightly compacted in the wild-type sperm as shown by the density of staining observed on electron microscopy (Fig. 5a,b), although it was heterogeneous with clear spots in sperm from Prm $1^{+/-}$mice (Fig. 5 c,d), as previously reported ${ }^{6,23}$. The flagellum of normal sperm is a bundle of nine fused pairs of microtubule doublets surrounding two central single microtubules-the so-called " $9+2$ " structure (Fig. 5e,f). Almost half of the microtubules in the $\mathrm{Prm}^{+/-}$sperm showed a disorganised arrangement of microtubule doublets or a loss of multiple doublets (Fig. $5 \mathrm{~g}-\mathrm{j}$ ).

Characterisation of sperm. The acrosome reaction (AR) is generally believed to be necessary for penetration of the zona pellucida. Because sperm from $\mathrm{Prm}^{+/-}$mice cannot fertilise eggs with a zona pellucida, we examined the AR status in sperm from the $\mathrm{Prm}^{+1-}$ mice. Coomassie brilliant blue $\mathrm{G} 250$ stain was used to directly visualise the acrosome under a bright field microscope. At the start of incubation ( 0 min), there was a tendency towards spontaneous AR, although the percentage of sperm with AR did not differ significantly and presented values of $6.3 \% \pm 4.3 \%$ in the $\mathrm{Prm}^{+/+}$mice and $21.5 \% \pm 6.4 \%$ in $\mathrm{Prm}^{+/-}$mice (Fig. 6a). Following sperm incubation for $90 \mathrm{~min}$ in the presence of $\mathrm{Ca}^{2+}$ ionophores, the percentage of sperm with AR in the Prm $1^{+/-}$mice was $50.6 \% \pm 0.4 \%$, which was significantly higher than that in the $P r m 1^{+/+}$mice $(17.4 \% \pm 4.3 \% ; P<0.01$, Fig. 6a), suggesting that the AR was highly induced in the $\mathrm{Prm1}^{+/-}$sperm.

We did not use computer-assisted semen analysis to examine the motility of spermatozoa from the Prm $1^{+/-}$ mice because it was too weak to detect by this method. Instead, we used phase-contrast microscopy. The motility of the spermatozoa from the $\mathrm{Prm}^{+/+}$mice was $50.7 \%$ and that of the spermatozoa from the Prm $^{+l-}$ mice was $7.8 \%(P<0.01$, Fig. $6 \mathrm{~b})$. The motility of sperm from the $P r m 1^{+/-}$mice was thus greatly reduced, and there was substantial variation in the velocity of both the sperm head along a straight line ans the flagellar beating (data not shown).

A reduction in the mitochondrial membrane potential (MMP) of sperm is reportedly associated with a reduction in sperm motility ${ }^{24}$. The MMP can be measured using 5,5',6,6 -tetrachloro- $1,1^{\prime}, 3,3^{\prime}$-tetraet hylbenzimidazolcarbocyanine iodide (JC-1) fluorescence. JC-1 labels mitochondria with a high membrane potential red and mitochondria with a low membrane potential green. Red-stained sperm appeared in the upper region of our plots and were considered healthy, whereas green-stained spermatozoa appeared in the lower region and were considered unhealthy or dead (Fig. $6 \mathrm{c})$. The mean red-to-green fluorescence ratio $(3.86 \pm 0.22)$ in the wild-type sperm was significantly higher than that in the $P r m 1^{+/-}$mice $(2.61 \pm 0.06 ; P<0.05$, Fig. $6 \mathrm{~d})$. The mean percentage of the highly fluorescent populations $(44.1 \% \pm 1.0 \%)$ in the $P r m 1^{+1+}$ sperm was significantly higher than that in the $\operatorname{Prm}^{+/-}$sperm $(18.2 \% \pm 5.2 \% ; P<0.05$, Fig. $6 \mathrm{~d})$, indicating that the percentage of unhealthy or dead sperm in the $\mathrm{PrmI}^{+/-}$mice was higher than that in the $\mathrm{Prml}^{+/+}$mice.

Following dataset filtration, dataset condensation via replacement of replicate spots with their averages, and control spot removal, the expression dataset contained 72,688 probes. As expected, the expression levels of Prm1, Prm2, Tnp1, and Tnp2 in the Prm1 ${ }^{+/-}$epididymis were lower $(72.46 \%, 67.11 \%, 75.76 \%$, and 65.79\%, 

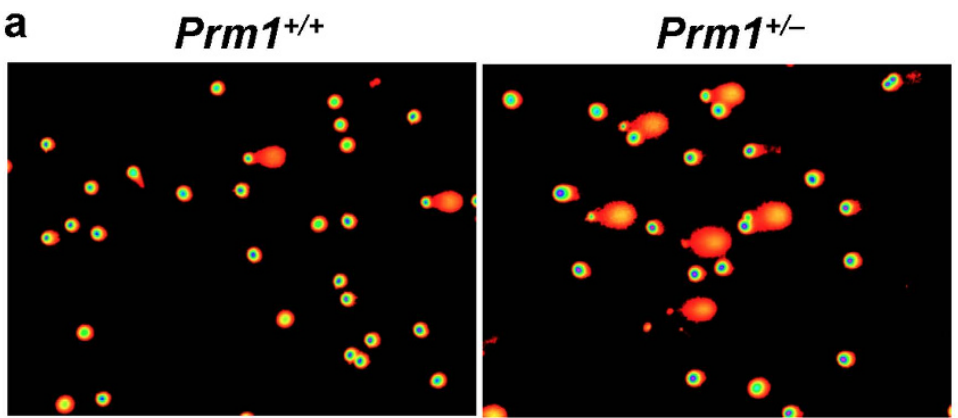

\section{b Tail length}

$\%$ DNA in tail

Tail moment
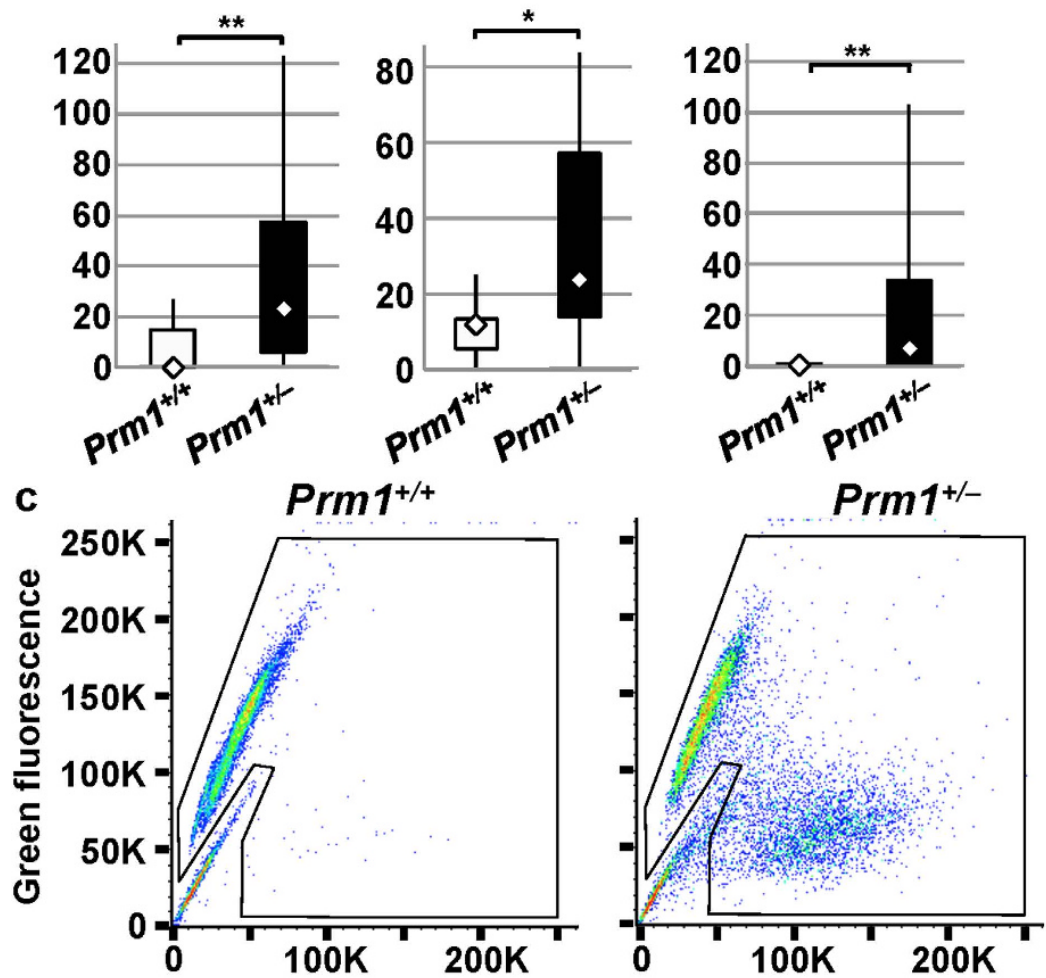

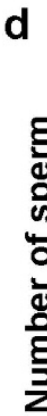

Red fluorescence

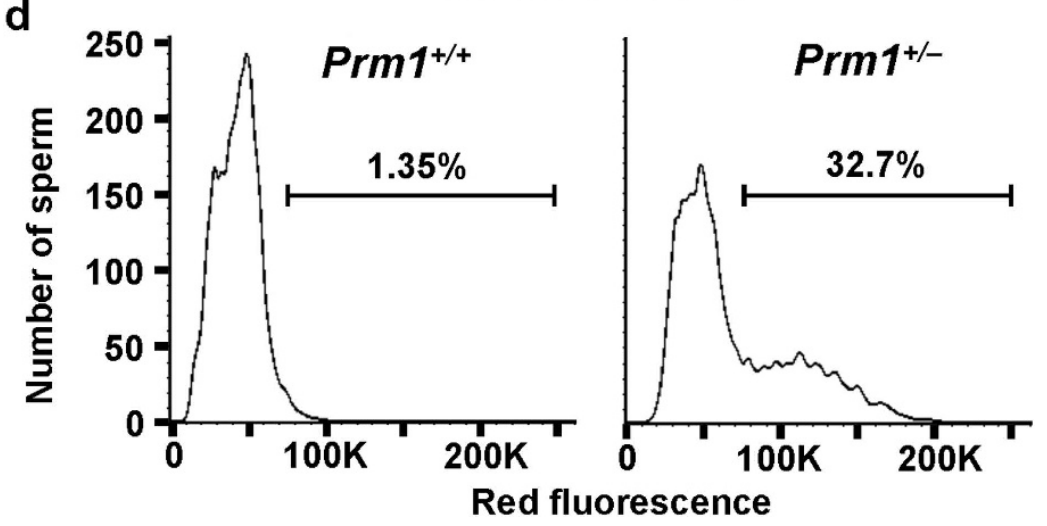

Figure 3. DNA destabilization. (a,b) Comet assay. a. Photographs of epididymal sperm comets. (b) DNA in the $\mathrm{Prm1}^{+/-}$sperm was destabilised, as judged by the increased indices of tail length, the \%DNA in the tail, and the tail moment. (c) SCSA cytogram. SCSA using acridine orange staining showed high levels of green fluorescence but little red fluorescence in the $\mathrm{Prml}^{+/+}$sperm and low levels of green fluorescence and high levels of red, fluorescence in the $\mathrm{PrmI}^{+/-}$sperm, suggesting a reduction of sperm DNA integrity in the Prm $1^{+/-}$ mice. (d) Histograms of the numbers of sperm showing red fluorescence. Sperm of Prm1 $1^{+/-}$mice showed biphasic peaks. Percentages of cells outside the main population are also shown. Comet parameters were analysed using the Mann-Whitney U-Test $\left({ }^{\star} P<0.05,{ }^{\star *} P<0.01\right)$. 


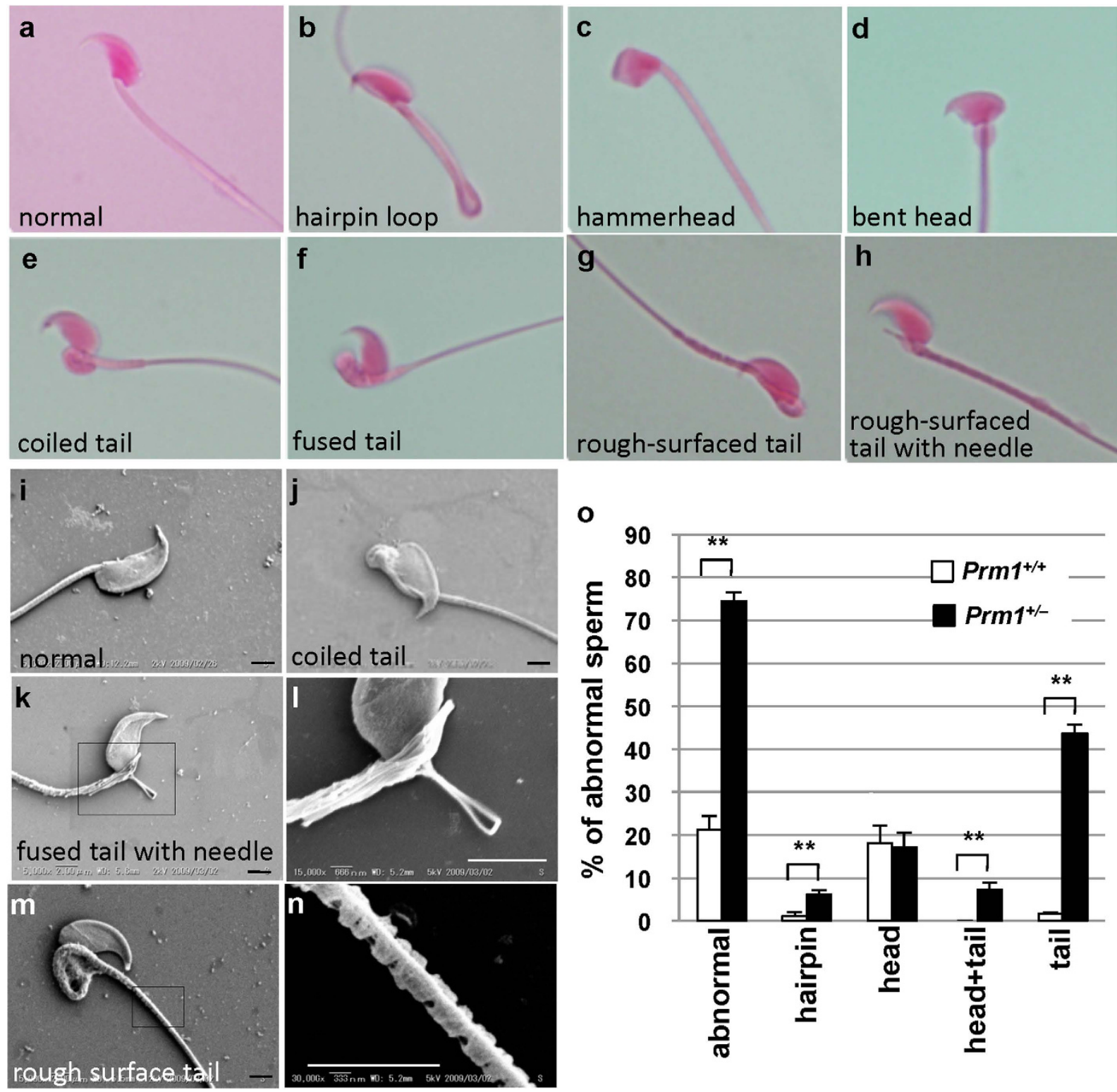

Figure 4. Sperm morphology, as indicated by eosin staining and scanning electron microscopy. (a-h) Eosin staining. (i-n) SEM. l, higher magnification of $(\mathbf{k})$. (n), Higher magnification of $(\mathbf{m}, \mathbf{o})$, frequencies of abnormal spermatozoa. Scale bar: $2 \mu \mathrm{m}$. Statistical analyses were performed using unpaired Student's t-tests $\left({ }^{\star} P<0.05\right.$, $\left.{ }^{* *} P<0.01\right)$.

respectively) than those in the $\operatorname{Prm} 1^{+/+}$epididymis. This finding is consistent with the data on the expression levels of sperm-specific nuclear protein genes (Fig. 1), thus confirming the reliability of the quality of the epididymal mRNA. The expression profiles in the Prm $1^{+/-}$epididymis differed by more than $200 \%$ from those in the Prm $1^{+/+}$ epididymis in only $495(0.68 \%)$ of the 72,688 probe sets, suggesting that the expression profiles in the two genotypes were similar (Fig. 6e) and that there was no obvious derangement of expression in the absence of PRM1.

\section{Discussion}

We demonstrated here that Prm $^{+/-}$sperm could fertilise zona-free oocytes in vitro, and Prm1 ${ }^{+/-}$mice born from these embryos did not exhibit phenotypic abnormalities except sperm morphological abnormalities. As expected, Prm $1^{+/-}$sperm showed chromatin decondensation and destabilisation, abnormal morphology, reduced motility, and enhanced AR; however, there was little derangement of gene-expression profiles in the sperm.

Previous studies ${ }^{5,6}$ have demonstrated that Prm1 or Prm2 male or female chimeras cannot produce offspring with Prm1- or Prm2-deficient alleles by natural mating, although sperm with Prm1- or Prm2-targeted alleles can be found in chimeras. Intracytoplasmic sperm injection (ICSI) also failed to obtain offspring using Prm2-deficient sperm. Previous researchers did not perform in vitro fertilisation using zone-free embryos. In both studies, they used the 129-derived ES cell line, whereas we used the TT2 ES cell line that were derived from BCF1 embryos. As previously reported ${ }^{25}$, the efficiency of ICSI in terms of the oocyte survival rate and the cleavage rate to the 
$\mathrm{Prm1}^{+/+}$
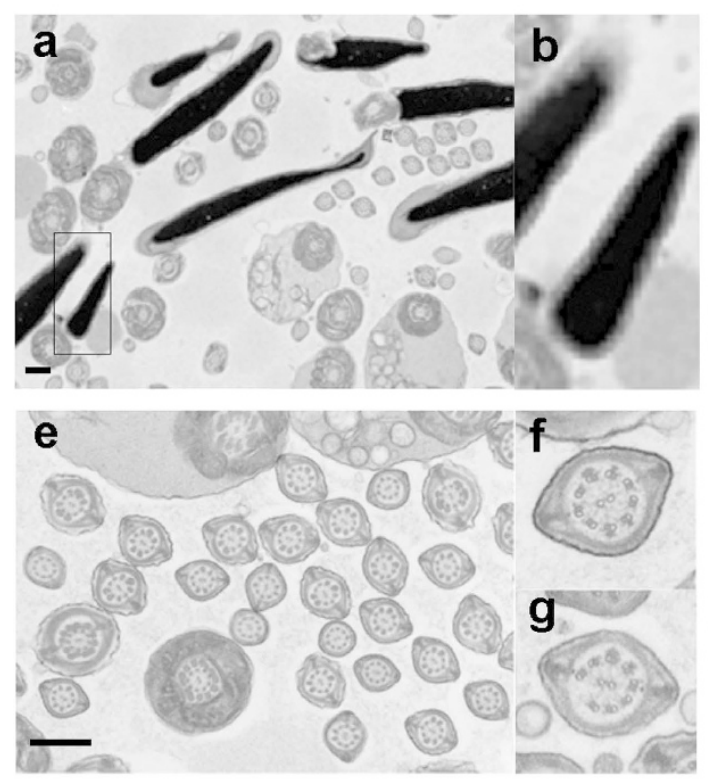
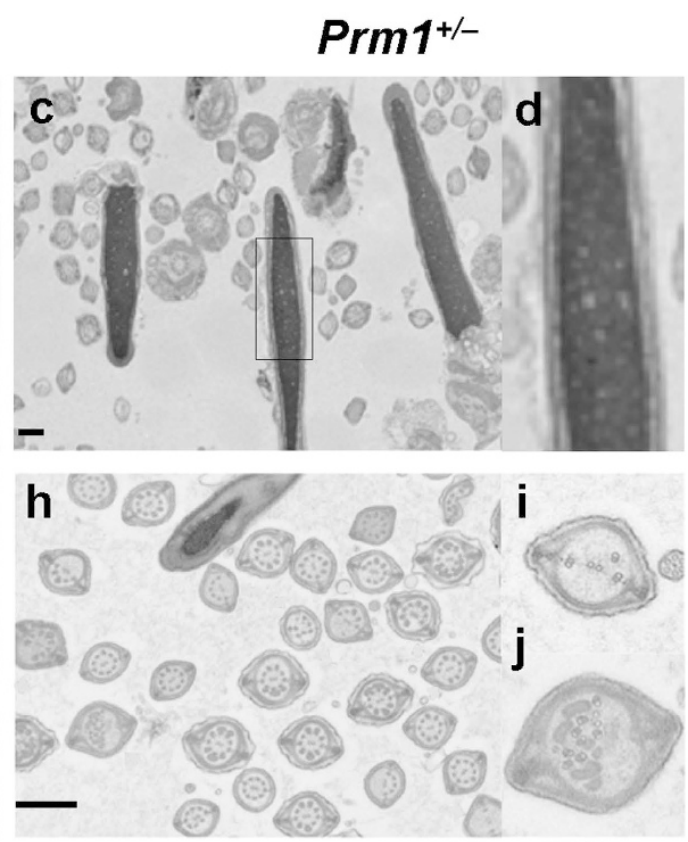

Bar, 500 nm

Figure 5. DNA decondensation and flagellum abnormalities under TEM. (a) $\mathrm{Prm}^{+/+}$sperm heads showing normal electron density. (b) Magnified view of the sperm head in (a). (c) Prm $1^{+/-}$sperm head showing heterogeneous electron density. (d) Magnified view of the sperm head in (c). (e) Ultrastructure of the Prm $1^{+/+}$ sperm flagellum showing a normal microtubule structure. (f,g) Magnified views of (e). (h) Ultrastructure of the $\mathrm{Prm}^{+/-}$sperm flagellum, showing an abnormal structure (arrows). (i,j) Magnified figure of the sperm head in (h). Scale bar: $500 \mathrm{~nm}$.

two-cell stage in the 129 strain were low. In addition, the phenotype analyses presented here suggest that the percentage of Prm1-deficient sperm that is compatible with development is low, which increases the difficulty of obtaining such sperm for ICSI.

In this study, we first used XO ES cells to produce female chimeras, which successfully produced male and female $\mathrm{Prm}^{+/-}$mice. Once we had obtained female $\mathrm{Prm}^{+/-}$mice, we could obtain male Prm1 $1^{+/-}$mice simply by mating the female $\mathrm{Prm}^{+/-}$mice with male $\mathrm{Prm}^{+/+}$mice. Alternatively, the sperm of Prm1 ${ }^{+/-}$mice could be used to obtain the next generation through IVF with zona-free oocytes. DNA damage induced in the sperm can be repaired in zygotes ${ }^{26-28}$, although matur sperm are incapable of repairing reactive oxygen species-induced DNA damage because these sperm lose their repair capabilities during spermatogenesis ${ }^{29}$. Generoso et al. demonstrated that paternal DNA can be repaired by maternal or zygotic factors ${ }^{30}$. Thus, the sperm DNA damage (if any) is not sufficiently severe to prevent the production of offspring and could be repaired after fertilization.

In sperm from the $\mathrm{Prm}^{+1-}$ mice, the relative amount of PRM1 decreased, whereas the amount of mature PRM2 decreased and that of the precursor forms of PRM2 increased. The same results have been observed in sperm from chimeras ${ }^{5}$. These findings suggest that PRM1 is involved in the processing of PRM2. CMA3 and $\mathrm{mBBr}$ assays can be used to determine the protamine content of sperm chromatin. Interestingly, both the CMA3 and $\mathrm{mBBr}$ assays indicated biphasic peaks, suggesting the presence of two types of sperm; one with normal levels of PRM and another with lower levels. Transcription of Prm1 and Prm2 is initiated at step seven during spermiogenesis $^{31}$, and these mRNAs are stored as cytoplasmic ribonucleoproteins before translation ${ }^{32}$. PRM1 synthesis starts in step 12 and PRM2 synthesis starts in step $13^{2}$. Although the genetically haploid spermatids are functionally diploid as a result of the sharing of gene products via their intercellular bridges ${ }^{33,34}$, PRM delivery from Prm $^{+}$ to $\mathrm{Prm}^{-}{ }^{-}$sperm may not be sufficient because of late translation of PRM1 during spermiogenesis.

Like us, Cho et al..$^{5}$ showed destabilisation of sperm DNA using the comet assay and SCSA. Both the comet assay and SCSA are thought to detect sperm DNA damage or integrity ${ }^{22,35}$, and DNA damage is considered to be the cause of infertility in Prm $1^{+/-}$mice ${ }^{5,6}$. However, we showed that viable offspring could be obtained from Prm1-deficient sperm using IVF and zona-free oocytes, suggesting that these methods can measure the stability and condensation of chromatin rather than critical DNA damage.

The infertility of $\mathrm{Prm1}^{+/-}$mice might be caused not by critical sperm DNA damage but by reduced sperm motility resulting from an abnormal tail structure and disturbed energy metabolism. In fact, tail defects have frequently been reported as the cause of impaired motility and infertility. These defects include the absence of a definitive fibrous sheath and a shortened flagellum in mice deficient in the A-kinase anchoring protein $4^{36}$; flagella with abnormal axonemes and aberrant acrosomal structures in mice deficient in phospholipase A2, group III ${ }^{37}$; morphologically abnormal sperm with a frequent loss of the sperm head and disorganisation of flagellar structures, such as the loss of the central pair of microtubules and disorganization of the outer dense fibres and fibrous sheath, in mice deficient in sperm-associated antigen $6^{38}$; and defective microtubule structures of the axoneme 

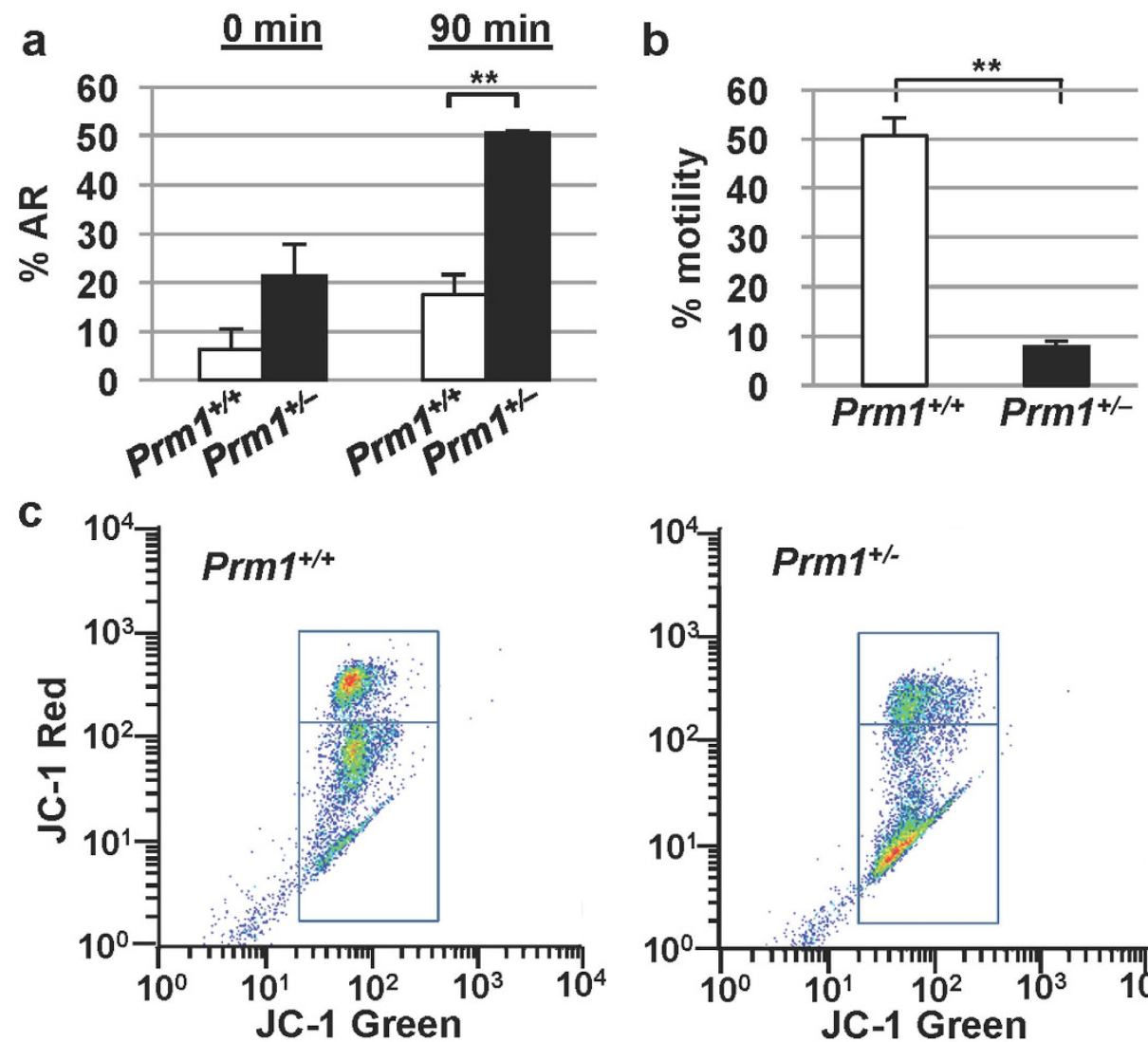

d
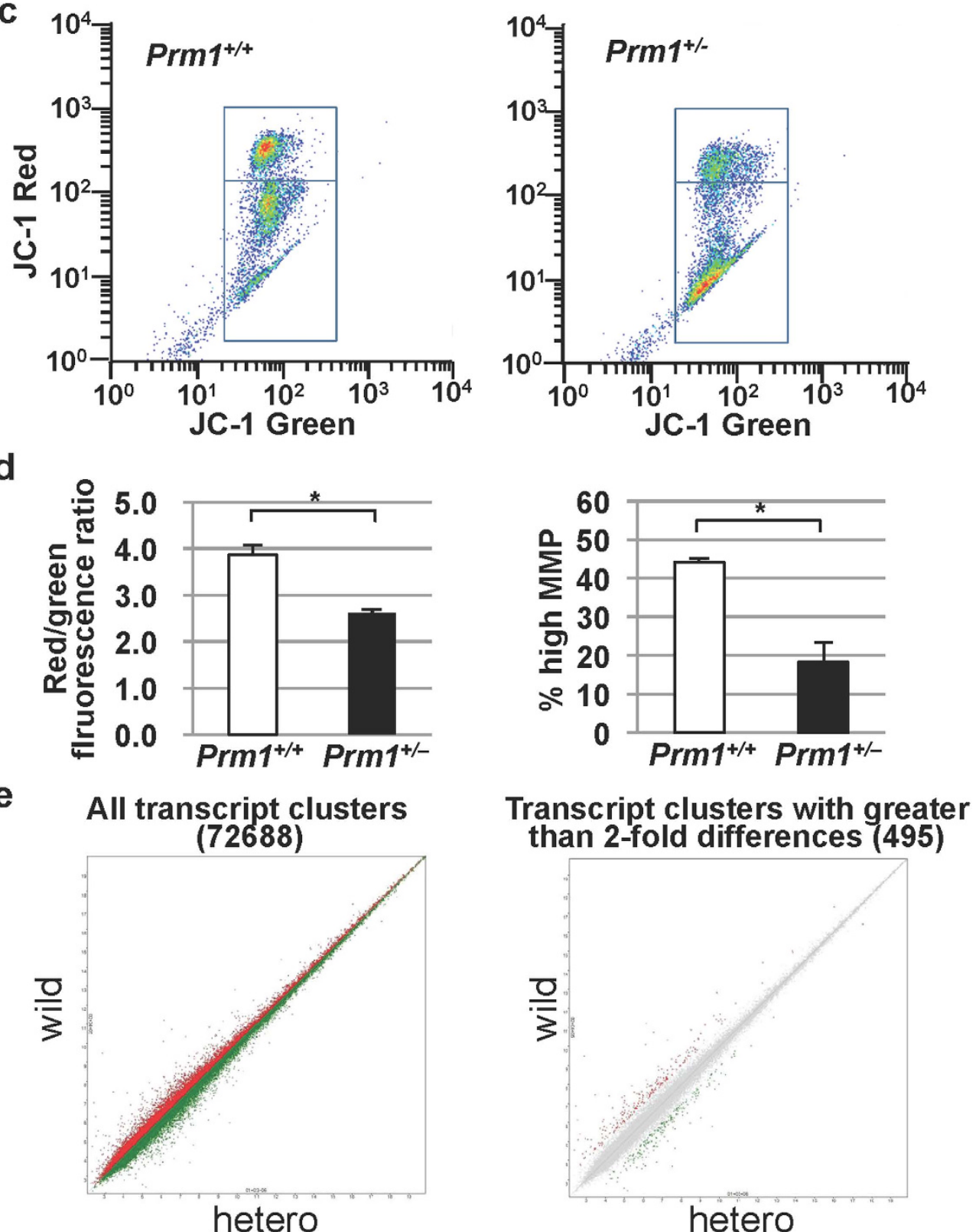

Figure 6. Characterisation of epididymal sperm. (a) Acrosome reaction (AR). The percentage of sperm with spontaneous ARs in the $\mathrm{Prml}^{+/-}$mice was significantly increased after sperm incubation for $90 \mathrm{~min}$. (b) Motility of spermatozoa, showing a significant reduction of motility in the $\mathrm{Prml}^{+/-}$mice. (c) Cytogram of the mitochondrial inner transmembrane potential. JC-1 labels mitochondria with high membrane potential orange (JC-1 aggregates) and mitochondria with low membrane potential green (JC-1 monomers). Orange-stained sperm appear in the upper right quadrant; green-stained spermatozoa appear in the lower right quadrant. (d) Histogram of JC-1 
staining. The red/green fluorescence ratio in the $\mathrm{Prm}^{+/-}$mice was significantly lower than that in the $\operatorname{Prm} 1^{+/+}$ mice. The percentage of sperm with a high mitochondrial membrane potential (MMP) in the Prm1 $1^{+/-}$mice was significantly lower than that in the $P r m 1^{+/+}$mice. (e) DNA microarray analysis. Both the scatter plot of the entire transcript cluster $(72,688)$ and the scatter plot of the transcripts clusters with more than a $200 \%$ difference $(495)$ between the $\mathrm{PrmI}^{+/+}$and $\mathrm{Prml}^{+/-}$mice showed similar expression profiles in the two mouse genotypes. Statistical analyses were performed using unpaired Student's t-tests $\left({ }^{*} P<0.05\right.$, $\left.{ }^{* *} P<0.01\right)$.

in mice with a partial deletion of the chromosome $8 \beta$-defensin cluster $^{39}$. In addition, motility can be reduced by metabolic disturbance because functionally active mitochondria are essential for flagellar movement ${ }^{40}$. Thus, a reduction in MMP as revealed by JC1 staining may cause a decrease in sperm motility. Although protamine binding reportedly silences gene expression during spermiogenesis ${ }^{41-43}$, there was no obvious derangement of expression patterns in the absence of PRM1. Therefore, disturbed energy metabolism may not be caused by disordered global gene expression. Other proteins, such as PRM2 and transition protein, may protect these genes from aberrant expression. The relationship between Prm1 deficiency and reduced sperm motility may be explained as follows. During spermatozoal maturation in the epididymis, the cysteines become progressively oxidized, thus forming inter- and intra-protamine disulfide bonds and further stabilizing both the chromatin ${ }^{44,45}$ and tail structures ${ }^{46,47}$. Zubkova et al. ${ }^{48}$ demonstrated that spermatozoa with fewer disulfide bonds caused by ageing are more susceptible to oxidative stress. Thus, Prm1-deficient spermatozoa may be more severely damaged by oxidative stress during maturation in the male reproductive tract. Taken together, these results suggest that exposure to oxidative radicals can cause changes in sperm morphology, thus leading to impaired spermatozoal motility.

AR was accelerated in the Prm $1^{+/-}$mice. In mammals, ejaculated sperm must complete capacitation to become competent to fertilise a mature oocyte. Capacitation involves several changes in the membrane properties and an increase in the intracellular calcium that drives motility and induction of the $\mathrm{AR}^{49}$. Only capacitated sperm can bind glycoproteins of the zona pellucida, undergo AR, and fertilise a mature oocyte. However, excessive intracellular calcium may induce microtubule defects and premature $\mathrm{AR}^{39}$. Such sperm will lose motility ${ }^{50}$ and the ability to firmly bind to the zona pellucida ${ }^{39}$ despite being capable of penetrating the egg ${ }^{51,52}$. It is currently unclear whether such an excessive increase in intracellular calcium level occurs in the absence of PRM1, and further studies will be required to address this question.

\section{Methods}

Generation of Prm1 mutant mice. To construct the targeting vector, the neo cassette was inserted into the NaeI site of the first exon of Prm1. The lengths of the homologous regions in the Prm 1 targeting vector were $6.8 \mathrm{~kb}$ and $0.9 \mathrm{~kb}$ at the $5^{\prime}$ and $3^{\prime}$ ends, respectively, of the neo cassette. The $9-\mathrm{kb}$ construct $\left(5^{\prime}\right.$-arm $/ \mathrm{Neo} / 3^{\prime}$-arm) for targeting was ligated into a pMCDT-A plasmid ${ }^{53}$ to generate the targeting vector. The targeting vectors were introduced into TT2-XO ES cells ${ }^{20}$ derived from an F1 embryo from a mating between C57BL/6 and CBA mice (Charles River Inc. Yokohama, Japan). G418-resistant clones were screened for homologous recombination by PCR, using the forward primer PAGN1 (5'-TCGTGCTTTACGGTATCGCCGCTCCCGATT- $\left.3^{\prime}\right)$ in the neo gene and the reverse primer Prm-R2 (5'-ATATCTCTAGGTTTTCAGACGAGGCA-3') on the $3^{\prime}$ end of the non-homologous region. The selected clones were confirmed by genomic Southern blot analyses (Supplementary Fig. 1). Targeted ES clones were injected into CD-1 eight-cell-stage embryos to generate chimeric mice. Foetuses and pups were genotyped by PCR using primers as described above. The mice were housed in an environmentally controlled room at the Center for Animal Resources and Development (CARD) at Kumamoto University. The experimental protocols that involved animals were approved by the Kumamoto University Ethics Committee for Animal Experiments (13-024) and all experiments were performed in accordance with the institute guidelines.

In vitro fertilization after removal of the zona pellucida. Superovulation was induced in female wild-type CD-1 mice (Charles River. Yokohama.Japan) and oocytes were collected 14 to $16 \mathrm{~h}$ after human chorionic gonadotropin administration. The cumulus cells were removed from the oocytes by hyaluronidase treatment. To remove the zona pellucida, the oocytes were treated with acidic Tyrode's solution ${ }^{54}$. Spermatozoa were isolated from the cauda epididymis and vas deferens of sexually mature mice and capacitated in HTF medium at $37^{\circ} \mathrm{C}$ for $1.5 \mathrm{~h}$. Spermatozoa $\left(1 \times 10^{5}\right)$ were added to intact and zona-free oocytes and incubated for $6 \mathrm{~h}$ at $37^{\circ} \mathrm{C}$ under $5 \% \mathrm{CO}_{2}$. The eggs were cultured to the blastocyst stage. Blastocysts obtained after IVF were transferred into day-3 pseudopregnant females. Foetuses were collected from pregnant mice on day 12 after IVF.

Sperm preparation. Spermatozoa obtained from age-matched adult mice were prepared from the cauda epididymis and vas deferens by gentle squeezing in mKSOM. Following the cell suspension was passed through a $70-\mu \mathrm{m}$ mesh filter, it was centrifuged at $400 \mathrm{~g}$ for $5 \mathrm{~min}$ and washed twice with $2 \mathrm{~mL}$ of PBS. Spermatozoa were sonicated to detach the sperm heads from the tails if needed.

Western blotting for sperm nuclear basic proteins. Sperm nuclear basic proteins were isolated and analysed as previously described ${ }^{55}$. A protease cocktail (P8340 Sigma) was used as the protease inhibitor. Gels were run and stained as previously described ${ }^{56}$. Proteins separated on the acid-urea gels were electroblotted onto an Immobilon- $\mathrm{P}^{\mathrm{SQ}}$ filter (Millipore). Part of each blot was stained with $0.25 \%$ Coomassie brilliant blue. The other parts of the blots were incubated for $1 \mathrm{~h}$ at room temperature with anti-PRM1 antiserum or anti-PRM2 antiserum (kindly donated by Dr. Rodney Balhorn) ${ }^{57}$. The blots were washed three times for $15 \mathrm{~min}$ each and then incubated with anti-mouse IgG antibody linked to horseradish peroxidase. The bound complexes were detected with ECL Plus reagents (Amersham Pharmacia) and exposed to $x$-ray film. 
RT-PCR analysis. Total RNA was isolated from the cauda epididymis and vas deferens of the Prm $1^{+/+}$and $\mathrm{Prm}^{+/-}$mice using ISOGEN reagent (Wako, Tokyo, Japan). Total RNA was reverse transcribed using a SuperScript III First-Strand Synthesis System for RT-PCR (Invitrogen). Amplifications were performed for 24 cycles. The primers used were as follows: Prm 1 forward primer 5'-ATGGCCAGATACCGATGCTG-3'; Prm 1 reverse primer 5'-CTAGTATTTTTTACACCTTATGG-3'; Prm 2 forward primer 5'-ATGGTTCGCTACCGAATGAGG-3'; Prm 2 reverse primer 5'-TTAGTGATGGTGCCTCCTACA-3'; Tnp 1 forward primer $5^{\prime}$-ATGTCGACC AGCCGCAAGC-3'; Tnp1 reverse primer 5'-TCACAAGTGGGATCGGTAATTG-3'; GAPDH (housekeeping gene) forward primer 5'-TGTCATCAACGGGAAGCCCA-3'; and GAPDH reverse primer 5'-TTGTCATGGATGACCTTGGC-3'.

CMA3 staining. CMA3 ${ }^{58}$ staining was performed as previously described ${ }^{59}$ with some modifications. Briefly, spermatozoa were incubated in staining solution for $20 \mathrm{~min}$ at room temperature in the dark.

$\mathrm{mBBr}$ thiol labelling assay. Thiol labelling was performed using $\mathrm{mBBr}$ as previously described ${ }^{48}$. Briefly, sperm were resuspended in PBS and aliquots were incubated with or without $1 \mathrm{mM}$ DTT to reduce sperm disulphides to reactive thiols. The samples were then washed twice and resuspended in PBS. A solution of $\mathrm{mBBr}$ was added to the sperm suspension for a final $\mathrm{mBBr}$ concentration of $1 \mathrm{mM}$, and the sample was incubated in the dark. The sperm were then washed in PBS and sonicated on ice in the dark until analysis.

Comet assay. A comet assay was performed by using a CometAssay kit (Trevigen). Briefly, spermatozoa $\left(1 \times 10^{5}\right.$ cells $\left./ \mathrm{mL}\right)$ in PBS were mixed with melted agarose and then immediately pipetted on to a CometSlide. The slides were immersed for $1 \mathrm{~h}$ on ice in pre-chilled lysis buffer, incubated for $18 \mathrm{~h}$ in lysis buffer containing $500 \mu \mathrm{g} / \mathrm{mL}$ proteinase $\mathrm{K}^{60}$. and then subjected to electrophoresis. Finally, the slides were immersed in chilled $70 \%$ ethanol and was stained with SYBR Green. The results were expressed as the 'tail length' and '\% DNA in tail', using TriTek Comet Score-Freeware v1.5 (TriTek Corp., Sumerduck, VA, USA).

Sperm chromatin structure assay (SCSA). Washed fresh sperm samples were diluted with TNE buffer to obtain a concentration of 1 to $2 \times 10^{6}$ cells $/ \mathrm{mL}$. A $0.2-\mathrm{mL}$ aliquot was then mixed with $0.4 \mathrm{~mL}$ of acid detergent. Thirty seconds later, $1.2 \mathrm{~mL}$ of AO staining solution was added ${ }^{22,61}$. The fluorescence of individual nuclei was measured with a FACSAria cytometer (BD Biosciences).

Fluorescence and flow cytometry analysis. Fluorescently labelled spermatozoa were analysed using fluorescence microscopy and a FACSAria flow cytometer (BD Biosciences). Data were processed with BD FACSDiva and FlowJo software. Data are representative of three or more experiments with over 5000 cells.

Sperm morphology. Sperm samples were fixed in buffered formol-saline and stained with eosin according to standard procedures.

For the SEM analysis, the specimens were fixed for $1 \mathrm{~h}$ with $2 \%$ glutaraldehyde in $0.1 \mathrm{M}$ phosphate buffer (pH 7.4). A drop of sperm suspension was then adhered to a poly-L-lysine-coated cover slip, which was washed three times with PBS. The specimens were dehydrated in a graded ethanol series and then freeze dried in a $t$-butanol freeze-drying apparatus (JEOL, JFD-320). The dried specimens were sputter-coated with platinum by an ion coater (JEOL, JFC-1600) and observed by SEM (Keyence, VE-9800).

For the TEM analysis, the specimens were fixed with $2 \%$ glutaraldehyde, post-fixed in $1 \% \mathrm{OsO}_{4}$, dehydrated through a graded ethanol series, and embedded in Quetol 812 (Nissin EM Co.). Ultra-thin sections were counterstained with uranyl acetate and lead citrate and then observed under a TEM (model H7100, Hitachi, Tokyo, Japan) at a $75-\mathrm{kV}$ accelerating voltage ${ }^{62}$.

Sperm motility. Sperm motility was evaluated immediately by placing a $10-\mu \mathrm{L}$ drop of diluted sperm suspension between a glass slide and a cover slip and counting the sperm under a phase-contrast microscope at $\times 1000$ magnification. Sperm motility was assessed as the $\%$ motile cells.

Assessment of acrosomal reaction. The AR was assessed according to a previously described method ${ }^{63}$. Mouse sperm was incubated in a $37^{\circ} \mathrm{C}$ water bath to allow capacitation. Then, the $\mathrm{Ca}^{2+}$ ionophore $\mathrm{A} 23187$ was added to induce the acrosomal reaction. Wet-mount preparations of semen samples were fixed in buffered formol-saline and the acrosome region was stained with $0.22 \%$ Coomassie brilliant blue before and after incubation at $37^{\circ} \mathrm{C}$ for $90 \mathrm{~min}$. Acrosomal staining was scored under a bright-field microscope. Ninety cells were counted in three wild-type and three $\operatorname{Prm}^{+/-}$mice.

JC-1 staining. JC-1 dye can be used as an indicator of MMP in a variety of cell types, including spermatozoa. JC-1 dye exhibits a potential-dependent accumulation in mitochondria, as indicated by a red fluorescence emission $(\sim 590 \mathrm{~nm})$. Thus, mitochondrial depolarization is indicated by a decrease in the red/green fluorescence intensity ratio. JC-1 staining was performed as previously described ${ }^{59}$.

DNA microarray analysis. RNA was isolated from sperm collected from the cauda epididymis and purified using an RNeasy Lipid Tissue Mini Kit (Qiagen, Valencia, CA). Total RNA (100 ng) was used to synthesise double-stranded cDNA (dsDNA). Anti-sense cRNA was synthesized from the dsDNA template and subsequently used to produce sense single-stranded cDNA (ssDNA). The ssDNAs were fragmented, end-labelled, and hybridised to a Genechip Mouse Transcript Assay 1.0 set (Affymetrix, Tokyo, Japan). Arrays were hybridised and scanned using a standard protocol. Microarray data were analysed using an Affymetrix Expression Console and Affymetrix Transcriptome Analysis Console (Affymetrix, Tokyo, Japan). 
Number of mice used for each experiment. The number of mice used for each experiment is shown in Supplementary Table 2 .

Statistical analysis. The comet parameters were analysed using the Mann-Whitney U-Test. In other experiments, statistical analyses were performed with unpaired Student's $t$-tests. The results are expressed as the means \pm SE. Differences were considered statistically significant at $P<0.05$.

\section{References}

1. Kistler, W. S., Henriksen, K., Mali, P. \& Parvinen, M. Sequential expression of nucleoproteins during rat spermiogenesis. Exp. Cell Res. 225, 374-381 (1996)

2. Balhorn, R., Weston, S., Thomas, C. \& Wyrobek, A. J. DNA packaging in mouse spermatids. Synthesis of protamine variants and four transition proteins. Exp. Cell Res. 150, 298-308 (1984).

3. Yelick, P. C. et al. Mouse protamine 2 is synthesized as a precursor whereas mouse protamine 1 is not. Mol. Cell. Biol. 7, 2173-2179 (1987).

4. Bench, G., Corzett, M. H., Kramer, C. E., Grant, P. G. \& Balhorn, R. Zinc is sufficiently abundant within mammalian sperm nuclei to bind stoichiometrically with protamine 2. Mol. Reprod. Dev. 56, 512-519 (2000).

5. Cho, C. et al. Haploinsufficiency of protamine-1 or -2 causes infertility in mice. Nat. Genet. 28, 82-86 (2001).

6. Cho, C. et al. Protamine 2 deficiency leads to sperm DNA damage and embryo death in mice. Biol. Reprod. 69, 211-217 (2003).

7. D’Occhio, M. J., Hengstberger, K. J. \& Johnston, S. D. Biology of sperm chromatin structure and relationship to male fertility and embryonic survival. Anim. Reprod. Sci. 101, 1-17 (2007).

8. Schluter, G. \& Engel, W. The rat Prm3 gene is an intronless member of the protamine gene cluster and is expressed in haploid male germ cells. Cytogenet. Cell Genet. 71, 352-355 (1995).

9. Grzmil, P. et al. Prm3, the fourth gene in the mouse protamine gene cluster, encodes a conserved acidic protein that affects sperm motility. Biol. Reprod. 78, 958-967 (2008).

10. Martin-Coello, J., Gomendio, M. \& Roldan, E. R. Protamine 3 shows evidence of weak, positive selection in mouse species (genus Mus)-but it is not a protamine. Biol. Reprod. 84, 320-326 (2011).

11. Aoki, V. W., Christensen, G. L., Atkins, J. F. \& Carrell, D. T. Identification of novel polymorphisms in the nuclear protein genes and their relationship with human sperm protamine deficiency and severe male infertility. Fertil. Steril. 86, 1416-1422 (2006).

12. de Yebra, L., Ballesca, J. L., Vanrell, J. A., Bassas, L. \& Oliva, R. Complete selective absence of protamine P2 in humans. J. Biol. Chem. 268, 10553-10557 (1993).

13. Kramer, J. A., Zhang, S., Yaron, Y., Zhao, Y. \& Krawetz, S. A. Genetic testing for male infertility: a postulated role for mutations in sperm nuclear matrix attachment regions. Genet Test 1, 125-129 (1997).

14. Queralt, R. \& Oliva, R. Identification of conserved potential regulatory sequences of the protamine-encoding P1 genes from ten different mammals. Gene 133, 197-204 (1993).

15. Queralt, R. \& Oliva, R. Demonstration of trans-acting factors binding to the promoter region of the testis-specific rat protamine P1 gene. Biochem. Biophys. Res. Commun. 208, 802-812 (1995).

16. Schlicker, M., Schnulle, V., Schneppel, L., Vorobev, V. I. \& Engel, W. Disturbances of nuclear condensation in human spermatozoa: search for mutations in the genes for protamine 1, protamine 2 and transition protein 1. Hum. Reprod. 9, 2313-2317 (1994).

17. Schnulle, V., Schlicker, M. \& Engel, W. A (GA)n repeat polymorphism in the human protamine 2 (PRM 2) gene. Hum. Mol. Genet. 3, 1445 (1994).

18. Tanaka, H. et al. Single nucleotide polymorphisms in the protamine-1 and -2 genes of fertile and infertile human male populations. Mol. Hum. Reprod. 9, 69-73 (2003).

19. Iguchi, N., Yang, S., Lamb, D. J. \& Hecht, N. B. An SNP in protamine 1: a possible genetic cause of male infertility? J. Med. Genet. 43, 382-384 (2006)

20. Nada, S. et al. Constitutive activation of Src family kinases in mouse embryos that lack Csk. Cell 73, 1125-1135 (1993).

21. Bianchi, P. G., Manicardi, G. C., Urner, F., Campana, A. \& Sakkas, D. Chromatin packaging and morphology in ejaculated human spermatozoa: evidence of hidden anomalies in normal spermatozoa. Mol. Hum. Reprod. 2, 139-144 (1996).

22. Evenson, D. P., Larson, K. L. \& Jost, L. K. Sperm chromatin structure assay: its clinical use for detecting sperm DNA fragmentation in male infertility and comparisons with other techniques. J. Androl. 23, 25-43 (2002).

23. Shirley, C. R., Hayashi, S., Mounsey, S., Yanagimachi, R. \& Meistrich, M. L. Abnormalities and reduced reproductive potential of sperm from Tnp1- and Tnp2-null double mutant mice. Biol. Reprod. 71, 1220-1229 (2004).

24. Gawlik, V. et al. Targeted disruption of Slc2a8 (GLUT8) reduces motility and mitochondrial potential of spermatozoa. Mol. Membr. Biol. 25, 224-235 (2008).

25. Ogonuki, N. et al. The effect on intracytoplasmic sperm injection outcome of genotype, male germ cell stage and freeze-thawing in mice. PLoS One 5, el1062 (2010).

26. Matsuda, Y., Seki, N., Utsugi-Takeuchi, T. \& Tobari, I. Changes in X-ray sensitivity of mouse eggs from fertilization to the early pronuclear stage, and their repair capacity. Int. J. Radiat. Biol. 55, 233-256 (1989).

27. Matsuda, Y. \& Tobari, I. Repair capacity of fertilized mouse eggs for X-ray damage induced in sperm and mature oocytes. Mutat. Res. 210, 35-47 (1989).

28. Matsuda, Y., Yamada, T. \& Tobari, I. Studies on chromosome aberrations in the eggs of mice fertilized in vitro after irradiation. I. Chromosome aberrations induced in sperm after X-irradiation. Mutat. Res. 148, 113-117 (1985).

29. Brandriff, B. \& Pedersen, R. A. Repair of the ultraviolet-irradiated male genome in fertilized mouse eggs. Science 211, 1431-1433 (1981).

30. Generoso, W. M., Cain, K. T., Krishna, M. \& Huff, S. W. Genetic lesions induced by chemicals in spermatozoa and spermatids of mice are repaired in the egg. Proc. Natl. Acad. Sci. USA 76, 435-437 (1979).

31. Mali, P. et al. Stage-specific expression of nucleoprotein mRNAs during rat and mouse spermiogenesis. Reprod. Fertil. Dev. 1, 369-382 (1989)

32. Hecht, N. B. Gene expression during male germ cell development. In: Cell and molecular biology of the testis (ed^(eds Desjardins, C., Ewing, L. L.). Oxford University Press (1993).

33. Braun, R. E., Behringer, R. R., Peschon, J. J., Brinster, R. L. \& Palmiter, R. D. Genetically haploid spermatids are phenotypically diploid. Nature 337, 373-376 (1989)

34. Morales, C. R., Wu, X. Q. \& Hecht, N. B. The DNA/RNA-binding protein, TB-RBP, moves from the nucleus to the cytoplasm and through intercellular bridges in male germ cells. Dev. Biol. 201, 113-123 (1998).

35. Collins, A. et al. The comet assay as a tool for human biomonitoring studies: the ComNet project. Mutat Res Rev Mutat Res 759, 27-39 (2014).

36. Miki, K. et al. Targeted disruption of the Akap4 gene causes defects in sperm flagellum and motility. Dev. Biol. 248, 331-342 (2002).

37. Sato H. et al. Group III secreted phospholipase A2 regulates epididymal sperm maturation and fertility in mice. J. Clin. Invest. 120, 1400-1414 (2010).

38. Sapiro, R. et al. Male infertility, impaired sperm motility, and hydrocephalus in mice deficient in sperm-associated antigen 6. Mol. Cell. Biol. 22, 6298-6305 (2002). 
39. Zhou, Y. S. et al. Partial deletion of chromosome 8 beta-defensin cluster confers sperm dysfunction and infertility in male mice. PLoS Genet. 9, e1003826 (2013).

40. Paoli, D. et al. Mitochondrial membrane potential profile and its correlation with increasing sperm motility. Fertil. Steril. 95, 2315-2319 (2011).

41. Carrell, D. T., Emery, B. R. \& Hammoud, S. Altered protamine expression and diminished spermatogenesis: what is the link? Hum. Reprod. Update 13, 313-327 (2007).

42. Martins, R. P., Ostermeier, G. C. \& Krawetz, S. A. Nuclear matrix interactions at the human protamine domain: a working model of potentiation. J. Biol. Chem. 279, 51862-51868 (2004).

43. Rathke, C. et al. Transition from a nucleosome-based to a protamine-based chromatin configuration during spermiogenesis in Drosophila. J. Cell Sci. 120, 1689-1700 (2007).

44. Calvin, H. I. \& Bedford, J. M. Formation of disulphide bonds in the nucleus and accessory structures of mammalian spermatozoa during maturation in the epididymis. J. Reprod. Fertil. Suppl. 13 Suppl 13, 65-75 (1971).

45. Loir, M. \& Lanneau, M. Structural function of the basic nuclear proteins in ram spermatids. J. Ultrastruct. Res. 86, 262-272 (1984).

46. Bedford, J. M. \& Calvin, H. I. Changes in -S-S- linked structures of the sperm tail during epididymal maturation, with comparative observations in sub-mammalian species. J. Exp. Zool. 187, 181-204 (1974).

47. Shalgi, R., Seligman, J. \& Kosower, N. S. Dynamics of the thiol status of rat spermatozoa during maturation: analysis with the fluorescent labeling agent monobromobimane. Biol. Reprod. 40, 1037-1045 (1989).

48. Zubkova, E. V., Wade, M. \& Robaire, B. Changes in spermatozoal chromatin packaging and susceptibility to oxidative challenge during aging. Fertil. Steril. 84 Suppl 2, 1191-1198 (2005).

49. Publicover, S., Harper, C. V. \& Barratt, C. $\left[\mathrm{Ca}^{2+}\right]$ i signalling in sperm-making the most of what you've got. Nat. Cell Biol. 9, 235-242 (2007).

50. Tanphaichitr, N. \& Hansen, C. Production of motile acrosome-reacted mouse sperm with nanomolar concentration of calcium ionophore A23187. Mol. Reprod. Dev. 37, 326-334 (1994).

51. Inoue, N., Satouh, Y., Ikawa, M., Okabe, M. \& Yanagimachi, R. Acrosome-reacted mouse spermatozoa recovered from the perivitelline space can fertilize other eggs. Proc. Natl. Acad. Sci. USA 108, 20008-20011 (2011).

52. Jin, M. et al. Most fertilizing mouse spermatozoa begin their acrosome reaction before contact with the zona pellucida during in vitro fertilization. Proc. Natl. Acad. Sci. USA 108, 4892-4896 (2011).

53. Yagi, T. et al. Homologous recombination at c-fyn locus of mouse embryonic stem cells with use of diphtheria toxin A-fragment gene in negative selection. Proc. Natl. Acad. Sci. USA 87, 9918-9922 (1990).

54. Hogan, B., Costantini, F. \& Lacy, E. Manipulating the Mouse Embryo. Cold Spring Harbor Laboratory Press 332 pp. (1986).

55. Giorgini, F., Davies, H. G. \& Braun, R. E. Translational repression by MSY4 inhibits spermatid differentiation in mice. Development 129, 3669-3679 (2002).

56. Lee, K., Haugen, H. S., Clegg, C. H. \& Braun, R. E. Premature translation of protamine 1 mRNA causes precocious nuclear condensation and arrests spermatid differentiation in mice. Proc. Natl. Acad. Sci. USA 92, 12451-12455 (1995).

57. Stanker, L. H., Wyrobek, A., McKeown, C. \& Balhorn, R. Identification of the binding site of two monoclonal antibodies to human protamine. Mol. Immunol. 30, 1633-1638 (1993).

58. Bizzaro, D. et al. In-situ competition between protamine and fluorochromes for sperm DNA. Mol. Hum. Reprod. 4, 127-132 (1998).

59. Baumber, J., Ball, B. A., Gravance, C. G., Medina, V. \& Davies-Morel, M. C. The effect of reactive oxygen species on equine sperm motility, viability, acrosomal integrity, mitochondrial membrane potential, and membrane lipid peroxidation. J. Androl. 21, 895-902 (2000).

60. Hauser, R., Singh, N. P., Chen, Z., Pothier, L. \& Altshul, L. Lack of an association between environmental exposure to polychlorinated biphenyls and p,p'-DDE and DNA damage in human sperm measured using the neutral comet assay. Hum. Reprod. 18, 2525-2533 (2003).

61. Ballachey, B. E., Hohenboken, W. D. \& Evenson, D. P. Heterogeneity of sperm nuclear chromatin structure and its relationship to bull fertility. Biol. Reprod. 36, 915-925 (1987).

62. Yoshinaga, K., Tanii, I., Oh-Oka, T. \& Toshimori, K. Transport and rearrangement of the intra-acrosomal protein acrin1 (MN7) during spermiogenesis in the guinea pig testis. Anat. Rec. 259, 131-140 (2000).

63. Larson, J. L. \& Miller, D. J. Simple histochemical stain for acrosomes on sperm from several species. Mol. Reprod. Dev. 52, 445-449 (1999).

\section{Acknowledgements}

We thank Dr. Rodney Balhorn for providing the Hup antibodies. We are grateful to Y. Suda and D. Kurokawa for their helpful discussions and comments. This work was supported by a Grant-in-Aid for Scientific Research (C) (22591828), Japan Society for the Promotion of Science (to N,T), by a Grant-in-Aid for Scientific Research (S) (21220010), Japan Society for the Promotion of Science (to K.Y.), and Scientific Support Programs for Cancer Research, Grant-in-Aid for Scientific Research on Innovative Areas, Ministry of Education, Culture, Sports, Science and Technology (to K.Y.).

\section{Author Contributions}

K.T., S.-i.Abe. and S.-i.A. conceived and designed the experiments. N.T., K.Y. and K.F. performed the experiments. N.T., Z.L. and K.Y. analysed the data. N.T., S.-i.A. and K.-i.Y. wrote the paper.

\section{Additional Information}

Supplementary information accompanies this paper at http://www.nature.com/srep

Competing financial interests: The authors declare no competing financial interests.

How to cite this article: Takeda, N. et al. Viable offspring obtained from Prm1-deficient sperm in mice. Sci. Rep. 6, 27409; doi: 10.1038/srep27409 (2016).

(c) (i) This work is licensed under a Creative Commons Attribution 4.0 International License. The images or other third party material in this article are included in the article's Creative Commons license, unless indicated otherwise in the credit line; if the material is not included under the Creative Commons license, users will need to obtain permission from the license holder to reproduce the material. To view a copy of this license, visit http://creativecommons.org/licenses/by/4.0/ 